\title{
Do not overlook an umbilical cord hernia before clamping
}

\author{
Mehmet Nevzat Cizmeci • Mehmet Kenan Kanburoglu • \\ Ahmet Zulfikar Akelma • Mustafa Mansur Tatli
}

Received: 4 March 2013 / Accepted: 19 March 2013 / Published online: 9 April 2013

(C) Springer-Verlag Berlin Heidelberg 2013

\begin{abstract}
An umbilical cord hernia is a rare midline abdominal defect. These masses may be easily overlooked at birth, which may result in an intestinal injury due to careless proximal application of the cord clamp. Herein, we present a newborn infant with an umbilical cord hernia who was managed by primary closure of the lesion.
\end{abstract}

Keywords Newborn · Umbilical cord hernia

A 2,340-g male infant was born at 38 weeks' gestation to a 34-year-old gravida 2 para 1 mother. The infant was on follow-up for intrauterine growth retardation during pregnancy, and upon delivery, he was detected to have a mass of $3 \mathrm{~cm}$ covered with an umbilical sac with visible intestinal loops inside (Fig. 1). The diagnosis was confirmed with physical examination of the sac and its contents, and measurement of the size of the mass.

A small omphalocele is called an umbilical cord hernia, which is a defect in the abdominal wall less than $4 \mathrm{~cm}$ in diameter. The defect arises in the first trimester as a result of failure of closure of the umbilical ring. The exteriorized sac contains only loops of bowel.

An umbilical cord hernia can be overlooked easily at birth, which may result in an intestinal injury due to careless proximal application of the cord clamp. Otherwise, these defects are easily managed by primary closure at birth and have an excellent outcome [1].
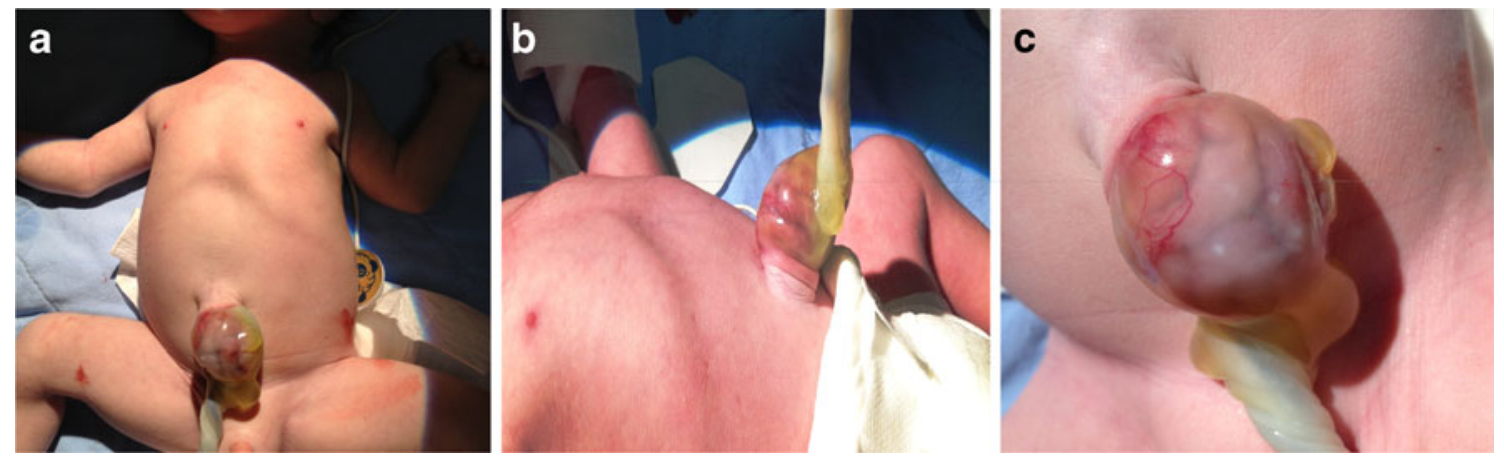

Fig. 1 A visible mass of $3 \mathrm{~cm}$ in the proximal portion of the umbilical cord (a). Lateral view of the same mass (b). A close-up of the mass shows clearly the intestinal loops trapped inside the sac, which is consistent with an umbilical cord hernia (c)

M. N. Cizmeci $(\bowtie) \cdot$ M. K. Kanburoglu • A. Z. Akelma •

M. M. Tatli

Department of Pediatrics, Fatih University Medical School,

Alparslan Turkes Cd. No: 57,

06510 Emek/Ankara, Turkey

e-mail: nevzatcizmeci@gmail.com

\section{Reference}

1. Poenaru D (2012) Abdominal wall problems. In: Gleason CA, Devaskar S (eds) Avery's diseases of the newborn, 9th edn. Elsevier-Saunders, Philadelphia, pp 1007-1015 